\title{
Endovascular renal sympathetic denervation to improve heart failure with reduced ejection fraction: the IMPROVE- HF-I study
}

\author{
L. Feyz · R. Nannan Panday · M. Henneman · F. Verzijlbergen · A. A. Constantinescu • B. M. van Dalen · \\ J. J. Brugts · K. Caliskan - M. L. Geleijnse · I. Kardys · N. M. Van Mieghem · O. Manintveld · J. Daemen
}

Accepted: 1 August 2021 / Published online: 5 October 2021

(C) The Author(s) 2021

\begin{abstract}
Introduction The aim of the present study was to assess the safety and efficacy of renal sympathetic denervation $(\mathrm{RDN})$ in patients with heart failure with reduced ejection fraction (HFrEF).

Methods We randomly assigned 50 patients with a left ventricular ejection fraction (LVEF) $\leq 35 \%$ and NYHA class $\geq \mathrm{II}$, in a 1:1 ratio, to either RDN and optimal medical therapy (OMT) or OMT alone. The primary safety endpoint was the occurrence of a combined endpoint of cardiovascular death, rehospitalisation for heart failure, and acute kidney injury at 6 months. The primary efficacy endpoint was the change in iodine123 meta-iodobenzylguanidine (123I-MIBG) heart-tomediastinum ratio (HMR) at 6 months.

Results Mean age was $60 \pm 9$ years, $86 \%$ was male and mean LVEF was $33 \pm 8 \%$. At 6 months, the primary
\end{abstract}

safety endpoint occurred in $8.3 \%$ vs $8.0 \%$ in the RDN and OMT groups, respectively ( $p=0.97)$. At 6 months, the mean change in late HMR was -0.02 (95\% CI: -0.08 to 0.12 ) in the RDN group, versus -0.02 (95\% CI: -0.09 to 0.12 ) in the OMT group ( $p=0.95)$ whereas the mean change in washout rate was 2.34 (95\% CI: -6.35 to 1.67$)$ in the RDN group versus -2.59 (95\% CI: -1.61 to 6.79$)$ in the OMT group ( $p$-value 0.09 ).

Conclusion RDN with the Vessix system in patients with HFrEF was safe, but did not result in significant changes in cardiac sympathetic nerve activity at 6 months as measured using ${ }^{123}$ I-MIBG.

Keywords Heart failure - Iodine-123 metaiodobenzylguanidine - Sympathetic overactivity · Renal sympathetic denervation

\section{What's new?}

- In patients with HFrEF, renal sympathetic denervation (RDN) did not result in a significant change in cardiac sympathetic nerve activity using specific ${ }^{123}$ I-MIBG nuclear imaging

- RDN appeared safe with the Vessix system, with no effect on blood pressure in patients with HFrEF

- NYHA class worsened significantly in the optimal medical therapy group at follow-up indicating the progressive nature of congestive heart failure

- A third of the patients in the RDN group improved to NYHA I

- Conducting larger and sham-controlled studies, assessing the effect of RDN on left ventricular performance and quality of life is warranted 


\section{Introduction}

Chronic heart failure is a major public health problem, with a prevalence of $1-2 \%$ in the adult population [1]. While pharmacological treatment for heart failure with reduced ejection fraction (HFrEF) has shown to prevent hospitalisation and improve quality of life and survival, its long-term prognosis remains poor justifying a persistent need for novel therapeutic strategies that improve both morbidity and mortality [2-6].

Increased sympathetic tone has been directly linked to severity of heart failure and adverse outcome $[7,8]$. In response to a chronic low-output state in HFrEF, neurohormonal adaptations occur such as the activation of the renin-angiotensin-aldosteronesystem (RAAS) and the sympathetic nervous system (SNS) in order to maintain vital organ perfusion [9, 10].

In the past decade, renal sympathetic denervation (RDN) emerged as a novel minimally invasive treatment option to reduce sympathetic tone and proved to significantly reduce blood pressure in hypertensive patients [11-14]. Promising findings were subsequently reported on the effects of RDN in HFrEF animal models $[15,16]$. Up to now, the clinical evidence for RDN in the treatment of HFrEF is limited and restricted to several small non-randomised studies $[17,18]$. In contrast to several studies with pharmaceutical agents, data correlating the effect of RDN on cardiac sympathetic tone as measured using iodine123 labelled meta-iodobenzylguanidine ( $\left.{ }^{123} \mathrm{I}-\mathrm{MIBG}\right)$ is lacking. The present study aimed to assess the safety and efficacy of RDN in patients with HFrEF as measured using ${ }^{123}$ I-MIBG at 6 months.

\section{Methods}

This present study is a single centre open label prospective randomised controlled trial designed to allocate 70 patients to treatment with RDN and optimal medical therapy (OMT) or OMT alone (1:1).

Due to the impact of several studies disputing the effect of RDN in patients with arterial hypertension, subsequent slow inclusion and the decision of the manufacturer of the device to halt further production of the Vessix V2 Renal Denervation System (Boston Scientific, Natick, MA, USA), inclusion was halted after the first 50 patients. This study was approved by our local ethics committee and all patients provided written informed consent (trialregister.nl, NTR number: NTR5328).

Patients were eligible for enrolment when the following inclusion criteria were met: left ventricular ejection fraction (LVEF) $\leq 35 \%$ (as assessed by echocardiography), New York Heart Association (NYHA) functional class $\geq$ II, age between 18 and 75 years, renal arteries suitable for RDN (i.e. baseline diameter stenosis $<30 \%$, main renal artery diameter of $\geq 3.5 \mathrm{~mm}$ and $\leq 7.0 \mathrm{~mm}$ for each kidney), a glomerular filtration rate
(eGFR) of $>30 \mathrm{ml} / \mathrm{min} / 1.73 \mathrm{~m}^{2}$. Exclusion criteria included: systolic office blood pressure $<110 \mathrm{~mm} \mathrm{Hg}$, recent $(<3$ months) stroke or myocardial infarction, acute heart failure (HF), presence of other medical diseases or conditions associated with a life expectancy of less than one year.

Work-up at baseline included laboratory analyses, $24 \mathrm{~h}$ ambulatory blood pressure measurement (24 h ABPM), echocardiography, ${ }^{123}$ I-MIBG, as well as a computed tomography (CT) scan to confirm renal artery eligibility. Clinical follow-up occurred at 1, 3 and 6 months and will be continued yearly up to 5 years. Follow-up renal artery imaging using CT was performed at 6 months in patients who underwent RDN.

\section{Study endpoints}

The primary safety endpoint included the occurrence of a combined endpoint of cardiovascular death, rehospitalisation for heart failure, and acute kidney injury at 6 months. The primary efficacy endpoint was the change in ${ }^{123} \mathrm{I}-\mathrm{MIBG}$ late heart-to-mediastinum ratio (HMR) at 6 months. Other safety parameters that were assessed at 6 months follow-up: major access site bleeding, change in renal function (measured in plasma: cystatin $\mathrm{C}$ and estimated by eGFR) and newly acquired renal artery stenosis and/or repeat renal artery intervention.

Secondary efficacy endpoints include (baseline vs 6-month follow-up): change in NYHA class, 6-minute walk test (6MWT), change in quality of life, echocardiographic endpoints, laboratory endpoints and change in diuretic dosage (based on a change in the defined daily dose, DDD) [19]. Quality of life and an overall physical and mental function survey (RAND36 and the Kansas City Cardiomyopathy questionnaire (KCCQ)) were used at baseline and at 6-month follow-up [20, 21]. All echocardiograms were assessed by dedicated imaging cardiologists unaware of the treatment allocation.

\section{3/-MIBG scintigraphy data acquisition and analysis}

For detailed data acquisition and analysis, our previous work should be used as a reference [22]. Calculation of WR was performed using the following formula (no correction for background): $\mathrm{WR}=\left(\mathrm{HMR}_{\text {early }}-\right.$ $\left.\mathrm{HMR}_{\text {late }}\right) /\left(\mathrm{HMR}_{\text {early }}\right) \times 100 \%$ [23]

\section{RDN procedure}

After administration of local anaesthesia, common femoral artery access was achieved by an ultrasoundguided puncture and a 6-Fr sheath was then introduced. Under fluoroscopic guidance, the short 6-Fr sheath was exchanged for an 8 -Fr RDN or an IMA tipped guiding sheath, to accommodate the Vessix V2 Renal Denervation System. The Vessix V2 sys- 


\section{Advertisement placed here.}

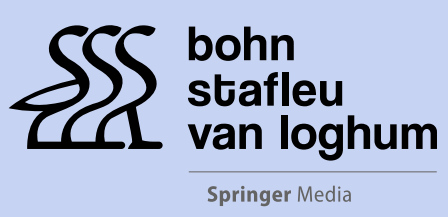

Houten 2021 


\section{Advertisement placed here.}

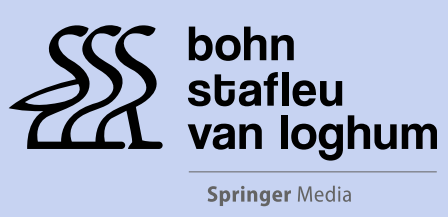

Houten 2021 


\section{Advertisement placed here.}

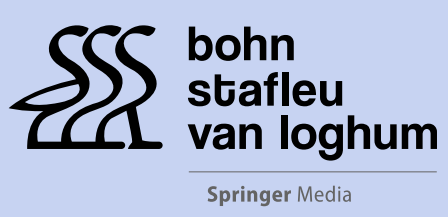

Houten 2021 


\section{Advertisement placed here.}

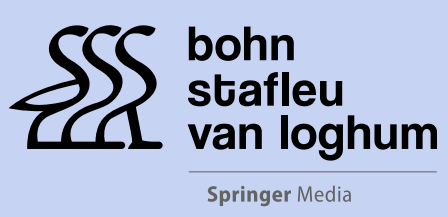

Houten 2021 
tem consists of an over-the-wire balloon catheter and a radiofrequency generator. After engaging the renal arteries, selective renal artery angiograms were obtained and an appropriate balloon size was chosen (4 [4 electrodes] to 7 [6 electrodes] $\mathrm{mm}$ ). Once balloon inflation was completed and the device activated, the generator raised the electrode temperature to $68^{\circ} \mathrm{C}$-the temperature at which treatment is conducted-and nerve denervation was carried out within $30 \mathrm{~s}$.

\section{Statistical analysis}

The study was designed to compare the primary efficacy endpoint, late HMR and washout rate (WR) derived from ${ }^{123}$ I-MIBG, in the treatment group versus control group (supplementary material for sample size calculation). Baseline categorical variables were expressed as counts and percentages. Differences in baseline categorical variables between randomly allocated treatment groups were compared using the chisquared test, Fisher's exact test or chi squared test for trend (NYHA class) when appropriate. Baseline continuous variables were described as mean \pm standard deviation (SD) when normally distributed. In case of non-normal data distributions, data were presented as median [interquartile range, IQR]. Continuous variables (such as HMR and WR, normally distributed) were compared between groups using independent samples $t$-test or paired samples $t$-test. To examine within-group changes, paired samples $t$-tests were used. Non-parametric tests (Wilcoxon signed-rank or Mann Whitney U test, when appropriate) were used to analyse differences in case of non-normal distributions. All statistical tests are two-tailed. A $p$ value $<0.05$ was considered statistically significant. Statistical analysis was performed using SPSS statistical analysis (version 24.0).

\section{Results}

\section{Clinical characteristics}

A total of 343 patients were assessed for eligibility, $50 / 343$ (14.6\%) were enrolled between August 2014 and June 2018 (Fig. 1). There were no significant differences in patient characteristics, haemodynamic parameters and baseline medications between both groups at the time of inclusion (Tab. 1). Mean age was $60 \pm 9$ years, $86 \%$ was male, $78 \%$ in NYHA class II

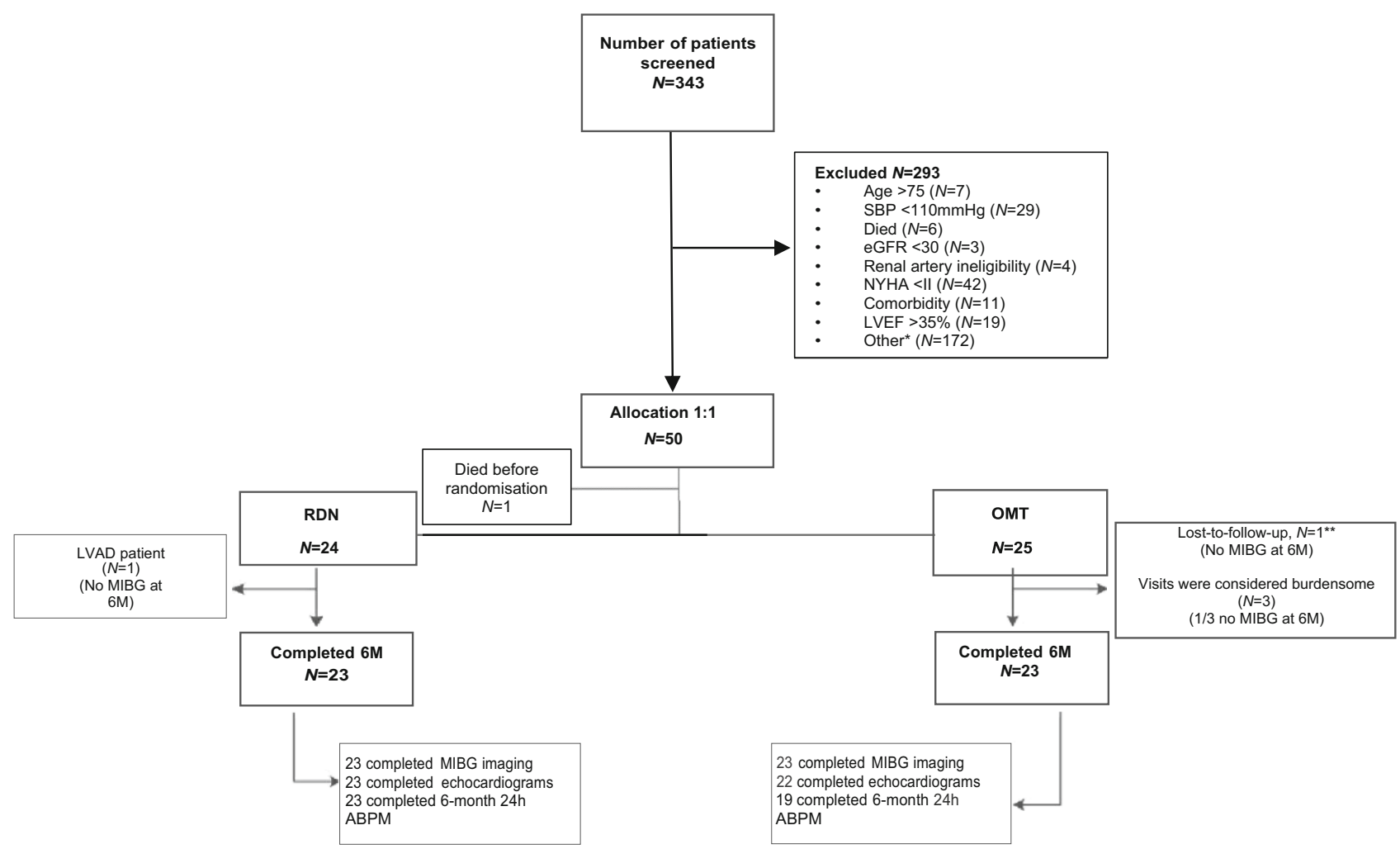

Fig. 1 Patients screened for eligibility, *Other= participation in other research studies $(N=9)$, waiting for heart transplantation $(N=14)$, refused consent, due to study burden, $(N=31)$ or other reasons $(N=60)$, non-compliance $(N=5)$, distance to the hospital $(N=6)$, not yet on OMT $(N=23)$, unable to contact $(N=24)$. ${ }^{* *}$ Lost-to-follow-up (in the OMTgroup) $N=1$ : patient retracted informed consent, still alive at 6 months. $A B P M$ ambulatory blood pressure measurement, eGFR estimated glomerular filtration rate, LVAD left ventricular assist device, $L V E F$ left ventricular ejection fraction, MIBG meta-iodobenzylguanidine, NYHA New York Heart Association, OMT optimal medical therapy, RDN renal sympathetic denervation, SBP systolic blood pressure, $6 M 6$ months 


\section{Original Article}

Table 1 Baseline characteristics

\begin{tabular}{|c|c|c|}
\hline & $\begin{array}{l}\text { RDN } \\
N=24\end{array}$ & $\begin{array}{l}\text { OMT } \\
N=25\end{array}$ \\
\hline Age, years & $60 \pm 8$ & $59 \pm 10$ \\
\hline Male $n,(\%)$ & $20(83.3)$ & $22(88.0)$ \\
\hline $\mathrm{BMI}, \mathrm{kg} / \mathrm{m}^{2}$ & $28.0 \pm 4.4$ & $27.9 \pm 5.2$ \\
\hline eGFR, $\mathrm{ml} / \mathrm{min}$ & $68.3 \pm 17.6$ & $69.8 \pm 20.8$ \\
\hline ICD/CRT, (\%) & $68 / 24$ & $64 / 20$ \\
\hline \multicolumn{3}{|l|}{ Cardiomyopathy } \\
\hline iCMP $n,(\%)$ & $15(62.5)$ & $14(56.0)$ \\
\hline $\operatorname{DCM} n,(\%)$ & $8(33.3)$ & $11(44.0)$ \\
\hline Other $n,(\%)$ & $1(4.2)$ & - \\
\hline \multicolumn{3}{|l|}{ Cardiovascular history (\%) } \\
\hline Prior Ml & $12(50.0)$ & $13(48.0)$ \\
\hline Prior PCl & $9(37.5)$ & $12(48.0)$ \\
\hline Prior CABG & $5(20.8)$ & - \\
\hline CVA & $3(12.5)$ & $1(4.0)$ \\
\hline \multicolumn{3}{|l|}{ Cardiovascular risk factors (\%) } \\
\hline Diabetes & $6(25.0)$ & $10(40.0)$ \\
\hline Hypertension & $14(58.3)$ & $10(40.0)$ \\
\hline Dyslipidaemia & $18(75.0)$ & $15(60.0)$ \\
\hline Smoker, current & $4(16.7)$ & $6(24.0)$ \\
\hline Family history of premature CVD & $7(29.2)$ & $9(36.0)$ \\
\hline \multicolumn{3}{|l|}{ Clinical parameters } \\
\hline 24h ABPM, mm Hg & $111 \pm 9 / 69 \pm 6$ & $108 \pm 9 / 66 \pm 5$ \\
\hline Office BP, mm Hg & $121 \pm 11 / 75 \pm 8$ & $124 \pm 19 / 75 \pm 14$ \\
\hline Heart rate, bpm & $70 \pm 9$ & $67 \pm 9$ \\
\hline NYHA II, (\%) & $17(70.8)$ & $21(84.0)$ \\
\hline NYHA III, (\%) & $7(29.2)$ & $4(16.0)$ \\
\hline \multicolumn{3}{|l|}{ Echocardiographic parameters } \\
\hline LVEF, \% & $32 \pm 7$ & $33 \pm 9$ \\
\hline LVEDD, mm & $72 \pm 7$ & $69 \pm 13$ \\
\hline LVESD, mm & $63 \pm 8$ & $61 \pm 15$ \\
\hline Mean number diuretics, $n$ (\%) & $2 \pm 1$ & $2 \pm 1$ \\
\hline \multicolumn{3}{|l|}{ Pharmacological therapy, $n$ (\%) } \\
\hline ACE-i/ATII-antagonist & $15(62.5) / 7(29.2)$ & $21(84.0) / 4(16.0)$ \\
\hline Calcium channel blockers & $2(8.3)$ & $2(8.0)$ \\
\hline Selective beta-blockers & $21(87.5)$ & $23(92.0)$ \\
\hline Diuretics/MRA & $20(83.3) / 21(87.5)$ & $25(100) / 19(76.0)$ \\
\hline Aspirin & $12(50.0)$ & $14(56.0)$ \\
\hline Statins & $17(70.8)$ & $18(72.0)$ \\
\hline \multicolumn{3}{|l|}{ Procedural characteristics } \\
\hline Number ablations L/R, median [IQR] & $11[6-12] / 10[7-12]$ & - \\
\hline Mean number of accessories L/R & $2 / 1$ & - \\
\hline
\end{tabular}

at baseline, ischaemic cardiomyopathy was present in $60 \%$ of the patients. Furthermore, mean baseline LVEF was $33 \pm 8 \%$, while mean left ventricular end-diastolic diameter (LVEDD) was $70 \pm 11 \mathrm{~mm}$. An implantable cardioverter-defibrillator (ICD)/cardiac resynchroni- sation therapy (CRT) device was present in $66 \%$ and $22 \%$ of patients respectively. Mean ambulatory blood pressure at baseline was $111 / 69 \pm 13 / 7 \mathrm{~mm} \mathrm{Hg}$. 
Table 2 Change in ${ }^{123}$ /-MIBG (primary efficacy endpoint)

\begin{tabular}{|c|c|c|c|c|c|c|c|c|}
\hline & RDN & & $\begin{array}{l}\text { Difference } \\
(95 \% \mathrm{Cl})\end{array}$ & ОМТ & & $\begin{array}{l}\text { Difference } \\
(95 \% \mathrm{Cl})\end{array}$ & $\begin{array}{l}\text { Mean between-group } \\
\text { difference }(95 \% \mathrm{Cl})\end{array}$ & $p$-value \\
\hline & Baseline & 6 months & & Baseline & 6 months & & & \\
\hline Early HMR & $2.14 \pm 0.41$ & $2.13 \pm 0.43$ & $-0.02(-0.09$ to 0.13$)$ & $2.44 \pm 0.49$ & $2.42 \pm 0.48$ & $-0.02(-0.13$ to 0.16$)$ & 0 (-0.18 to 0.18$)$ & 1.00 \\
\hline Late HMR & $1.92 \pm 0.43$ & $1.90 \pm 0.47$ & $-0.02(-0.08$ to 0.12$)$ & $2.15 \pm 0.47$ & $2.13 \pm 0.48$ & $-0.02(-0.09$ to 0.12$)$ & $-0.004(-0.14$ to 0.13$)$ & 0.95 \\
\hline WR & $11.3 \pm 7.8$ & $13.7 \pm 8.2$ & $2.34(-6.35$ to 1.67$)$ & $14.8 \pm 11.5$ & $12.2 \pm 9.0$ & $-2.59(-1.61$ to 6.79$)$ & $4.93(-0.73$ to 10.6$)$ & 0.09 \\
\hline
\end{tabular}

\section{Change in ${ }^{123} /-M I B G$}

No significant change was seen in late HMR and WR at 6 months between the RDN group and the OMT group respectively (Tab. 2). At 6 months, the mean change in late HMR was -0.02 (95\% CI: -0.08 to 0.12$)$ in the RDN group, versus -0.02 (95\% CI: -0.09 to 0.12 ) in the OMT group ( $p$-value for mean between group difference $=0.95$ ), whereas the mean change in WR was 2.34 (95\% CI: -6.35 to 1.67 ) in the RDN group versus -2.59 (95\% CI: -1.61 to 6.79 ) in the OMT group ( $p$-value for mean between group difference $=0.09$ ) .

\begin{tabular}{|c|c|c|}
\hline Endpoint & RDN & OMT \\
\hline Total events (\%) & 7/24 (29.2) & $10 / 25(40.0)$ \\
\hline $\begin{array}{l}\text { a Primary safety end- } \\
\text { point }\end{array}$ & 2/24 (8.3) & $2 / 25(8.0)$ \\
\hline \multicolumn{3}{|l|}{$\begin{array}{l}\text { Specific events within } \\
6 M\end{array}$} \\
\hline - Death & $0 / 24$ & $0 / 25$ \\
\hline - Myocardial infarction & $0 / 24$ & $2 / 25(8.0)$ \\
\hline - New-onset of ESRD & $0 / 24$ & $0 / 25$ \\
\hline $\begin{array}{l}\text { - Renal artery interven- } \\
\text { tion }\end{array}$ & $0 / 24$ & $0 / 25$ \\
\hline - Stroke & $0 / 24$ & $0 / 25$ \\
\hline - Hospitalisation for HF & $2 / 24(8.3)^{b}$ & $2 / 25(8.0)$ \\
\hline - Hospitalisation for AF & $1 / 24(4.2)$ & $1 / 25(4.0)$ \\
\hline $\begin{array}{l}\text { - Hospitalisation non- } \\
\text { cardiac }\end{array}$ & $0 / 24$ & $\begin{array}{l}2 / 25(8.0) \\
\text { (colon carcinoma, non- } \\
\text { Hodgkin lymphoma) }\end{array}$ \\
\hline $\begin{array}{l}\text { - New renal artery } \\
\text { stenosis }\end{array}$ & $1 / 24(4.2)$ & $0 / 25$ \\
\hline $\begin{array}{l}\text { - Side effects medica- } \\
\text { tion }\end{array}$ & $\begin{array}{l}\text { 2/24 (8.3) } \\
\text { (statin-induced myalgia, } \\
\text { amiodarone-induced } \\
\text { hyperthyroidism) }\end{array}$ & - \\
\hline $\begin{array}{l}A F \text { atrial fibrillation, ESRD } \\
\text { ventricular tachycardia } \\
\text { a The primary safety endp } \\
\text { point of cardiovascular de } \\
\text { kidney injury at } 6 \text { months } \\
\text { b } N=1 \text { received a LVAD (I }\end{array}$ & $\begin{array}{l}\text { end-stage renal disease, } \\
\text { oint includes the occurren } \\
\text { left ventricular assist devic }\end{array}$ & $\begin{array}{l}\text { HF heart failure, } V T \\
\text { ce of a combined end- } \\
\text { eart failure and acute } \\
\text { e) }\end{array}$ \\
\hline
\end{tabular}

\section{Safety}

The primary safety endpoint occurred in $2 / 24$ patients in the RDN group (8.3\%) vs $2 / 25$ patients in the OMT group $(8.0 \%)$ respectively $(p=0.97)$. In $3 / 24(12.5 \%)$ patients, a minor access site bleeding was observed (all small haematomas with no further clinical consequences), no further peri-procedural complications occurred. In the RDN group, one patient received a left ventricular assist device (LVAD) due to refractory heart failure. Safety events are described in Tab. 3. eGFR remained unchanged in both cohorts; in the RDN group: $68 \pm 17 \mathrm{ml} / \mathrm{min}$ at baseline vs $68 \pm 20 \mathrm{ml} / \mathrm{min}$ at 6 months, $p=0.98$. Similar findings were seen in the OMT group: $70 \pm 19 \mathrm{ml} / \mathrm{min}$ vs $71 \pm 21 \mathrm{ml} / \mathrm{min}, p=0.94$ (see Table S1 in Electronic Supplementary Material [ESM]).

See supplementary online material for details on secondary endpoints.

\section{Discussion}

RDN in patients with HFrEF did not result in a significant change in cardiac sympathetic nerve activity as measured using ${ }^{123}$ I-MIBG late HMR and WR at 6 months. The therapy appeared safe. A significant difference was observed in LVEDD in the RDN group, and $26 \%$ of patients in the treatment group were in NYHA class I versus none in the control-group.

Percutaneous RDN was introduced about 10 years ago as a minimal invasive treatment option for patients with resistant hypertension, a condition linked to sympathetic overactivity [24]. Sympathetic overactivity proved to contribute to the progression of myocardial cell injury and left ventricular dysfunction in patients with HF and a significant correlation was found between the severity of overactivity and NYHA class [25]. As a result to the chronic low-output state in HFrEF, elevated sympathetic tone stimulates renin release by the kidneys, leading to sodium retention, volume expansion and renal vasoconstriction in order to maintain vital organ perfusion. However, due to a subsequent increase in peripheral resistance, myocardial contractility and increase in heart rate prognosis worsens. An inverse association was found between norepinephrine release and survival [26]. Hu- 
man data from the REACH pilot study showed that $\mathrm{RDN}$ in seven patients with congestive HF was safe and associated with a significant increase in 6MWT [18]. A randomised study presented by Taborsky et al., showed that RDN in patients with more advanced heart failure (mean LVEF was $25 \%, N=51$ ) resulted in significant improvements in LVEF, left ventricular end-systolic diameter (LVESD) and LVEDD as well as in NT-pro-BNP while no change was seen in patients with OMT alone [17]. For reasons unknown, the study was never published.

To the best of our knowledge, our study is the first to assess the effect of RDN in patients with HFrEF using ${ }^{123}$ I-MIBG imaging to assess cardiac sympathetic nerve activity. HMRs remained unchanged at 6 months in both arms. While we aimed to enrol patients with symptomatic HFrEF, the vast majority of the patients in our study were in NYHA class II with relatively low NT-pro-BNP values, suggesting a less severe HF phenotype. The latter could have explained part of the lack of effect in the present study and should be put into perspective due to the fact that our study was one of the first dedicated studies on the safety and efficacy of RDN in heart failure. Whether a more pronounced effect can be observed in patients with more advanced or unstable heart failure should be assessed in future dedicated studies.

The relatively low risk profile of our patients could also explain the higher than expected baseline HMRs in our study as compared to previous studies on the topic with baseline late HMRs in the range of 1.2 to 1.6 in patients with more pronounced heart failure and late HMRs of $2.5 \pm 0.3$ in healthy control [27]. The same applies for the WR found in our study which, being around $12 \%$, were significantly below the threshold of $27 \%$ associated with poor prognosis [28]. This might suggest that the stable HF population studied in the present study was on relatively well controlled heart failure therapy in which the additional treatment with RDN did not add substantially on top of preexistent OMT to improve cardiac sympathetic nerve activity.

Although our study was not powered to detect a difference in clinical endpoints, the overall rate of HF-related events at 6 months in the present study was low which might illustrate the relatively low risk profile of the patients included.

Based on the data available at the time of our study design, a significant blood pressure lowering effect of RDN was anticipated in patients with hypertension. This raised concerns about a potential blood pressure lowering effect of RDN in HF patients which might have forced down-titration of HF drugs. The latter made that we refrained from including patients with a baseline systolic blood pressure $<110 \mathrm{~mm} \mathrm{Hg}$ and might have resulted in the HFrEF population at relatively low risk. Finally, in contrast to previous studies suggesting a significant change in LVEF following RDN, no change in LVEF was found in the present study. Conversely, we did observe a small, albeit significant, decrease in LVEDD following RDN. The latter results, however, should be interpreted with caution given the known variability in measurements derived from transthoracic echocardiography. However, we did observe a significant decrease in the peak late diastolic filling velocity in the treatment arm, which could implicate an improvement in left ventricular relaxation [29].

\section{Study limitations}

The current study has a number of limitations. First, we enrolled a smaller number of patients than first intended due to slow inclusion rates. Therefore, the study was underpowered to reach its primary efficacy endpoint. Second, we cannot exclude the fact that we might have used a less efficacious RDN system. Whether the use of a different technology in the present study would have altered our findings remains unknown. Third, we included a lower risk HF phenotype ( $80 \%$ with NYHA II). Finally, the present trial was an open label trial and not sham-controlled.

\section{Conclusion}

RDN with the Vessix system in patients with HFrEF was safe, but did not result in significant changes in cardiac sympathetic nerve activity at 6 months as measured using ${ }^{123}$ I-MIBG.

Acknowledgements Bep Sonneveld, Nel Slingerland, Marga Jongenotter and Michelle Heijkoop are gratefully acknowledged for their support and help in screening patients for eligibility at the outpatient clinic. Dr. Marco van Gent is gratefully acknowledged for referring patients to our trial.

Funding The work was supported by Boston Scientific and the Thorax Foundation.

Conflict of interest J. Daemen received institutional grant/ research support from Abbott Vascular, Biotronik, Boston Scientific, Acist Medical, Medtronic and PulseCath, and consultancy and speaker fees from Acist medical, Boston Scientific, ReCor Medical, Medtronic and Pulse Cath. N.M. Van Mieghem received institutional grant/research support from Abbott Vascular, Boston Scientific, Medtronic, Edwards Lifesciences, Biotronik, ACIST Medical, PulseCath and is advisor/ consultant to Abbott Vascular, Boston Scientific, Medtronic, PulseCath. L. Feyz, R. Nannan Panday, M. Henneman, F. Verzijlbergen, A.A. Constantinescu, B.M. van Dalen, J.J. Brugts, K. Caliskan, M.L. Geleijnse, I. Kardys, and O. Manintveld declare that they have no competing interests.

Open Access This article is licensed under a Creative Commons Attribution 4.0 International License, which permits use, sharing, adaptation, distribution and reproduction in any medium or format, as long as you give appropriate credit to the original author(s) and the source, provide a link to the Creative Commons licence, and indicate if changes were made. The images or other third party material in this article are included in the article's Creative Commons licence, unless indicated otherwise in a credit line to the material. If material is not included in the article's Creative Commons licence and 
your intended use is not permitted by statutory regulation or exceeds the permitted use, you will need to obtain permission directly from the copyright holder. To view a copy of this licence, visit http://creativecommons.org/licenses/by/4.0/.

\section{References}

1. Mosterd A, Hoes AW. Clinical epidemiology of heart failure. Heart. 2007;93:1137-46.

2. Cleland JG, Daubert JC, Erdmann E, et al. The effect of cardiac resynchronization on morbidity and mortality in heart failure. NEngl J Med. 2005;352:1539-49.

3. Zinman B, Wanner C, Lachin JM, et al. Empagliflozin, cardiovascular outcomes, and mortality in type 2 diabetes. NEngl J Med. 2015;373:2117-28.

4. Garg R, Yusuf S. Overview of randomized trials of angiotensin-converting enzyme inhibitors on mortality and morbidity in patients with heart failure. Collaborative Group on ACEInhibitor Trials. JAMA. 1995;273:1450-6.

5. Butler J, Young JB, Abraham WT, et al. Beta-blocker use and outcomes among hospitalized heart failure patients. J Am Coll Cardiol. 2006;47:2462-9.

6. McMurray JJ, Packer M, Desai AS, et al. Angiotensinneprilysin inhibition versus enalaprilin heartfailure. NEngl JMed. 2014;371:993-1004.

7. Cohn JN, Levine TB, Olivari MT, et al. Plasma norepinephrine as a guide to prognosis in patients with chronic congestive heartfailure. NEnglJ Med. 1984;311:819-23.

8. Ferguson DW, Berg WJ, Sanders JS. Clinical and hemodynamic correlates of sympathetic nerve activity in normal humans and patients with heart failure: evidence from direct microneurographic recordings. J Am Coll Cardiol. 1990;16:1125-34.

9. Chaggar PS, Malkin CJ, Shaw SM, et al. Neuroendocrine effects on the heart and targets for therapeutic manipulation in heartfailure. Cardiovasc Ther. 2009;27:187-93.

10. Kemp CD, Conte JV. The pathophysiology of heart failure. Cardiovasc Pathol. 2012;21:365-71.

11. Azizi M, SapovalM, GosseP, etal. Optimumandstepped care standardised antihypertensive treatment with or without renaldenervationfor resistanthypertension (DENERHTN): a multicentre, open-label, randomised controlled trial. Lancet. 2015;385:1957-65.

12. Townsend RR, Mahfoud F, Kandzari DE, et al. Catheterbased renal denervation in patients with uncontrolled hypertension in the absence of antihypertensive medications (SPYRALHTN-OFFMED): a randomised, sham-controlled, proof-of-concept trial. Lancet. 2017;390:2160-70.

13. Azizi M, Schmieder RE, MahfoudF, etal. Endovascularultrasoundrenaldenervation to treathypertension(RADIANCEHTNSOLO): a multicentre, international, single-blind, randomised, sham-controlled trial. Lancet. 2018;391:2335-45.

14. Smith PA, Graham LN, Mackintosh AF, et al. Relationship between central sympathetic activity and stages of human hypertension. Am J Hypertens. 2004;17:217-22.
15. Polhemus DJ, Trivedi RK, Gao J, et al. Renal sympathetic denervation protects the failing heart via inhibition of neprilysin activity in the kidney. J Am Coll Cardiol. 2017;70:2139-53.

16. Sharp TE 3rd, Polhemus DJ, Li Z, et al. Renal Denervation prevents heart failure progression via inhibition of the Renin-Angiotensin system. J Am Coll Cardiol. 2018;72:2609-21.

17. Taborsky M, Lazarova ML, Vaclavik J. The effect of renal denervation in patients with advanced heart failure. Eur HeartJ. 2012;33:517.

18. Davies JE, Manisty CH, Petraco R, et al. First-in-man safety evaluation of renal denervation for chronic systolic heart failure: primary outcome from REACH-Pilot study. Int J Cardiol. 2013;162:189-92.

19. World Health Organization Collaborating Centre for Drug Statistics Methodology. ATC Classification Index with DDDs. 2018.

20. Aaronson NK, Muller M, Cohen PDA, et al. Translation, validation, and norming of the Dutch language version of the SF-36 Health Survey in community and chronic disease populations. JClin Epidemiol. 1998;51:1055-68.

21. Green CP, Porter CB, Bresnahan DR, Spertus JA. Development and evaluation of the Kansas City Cardiomyopathy Questionnaire: a new health status measure for heart failure. JAm Coll Cardiol. 2000;35:1245-55.

22. Feyz L, Henneman M, Verzijlbergen F, et al. Renal sympathetic denervation in patients with vasospastic angina. J Nucl Cardiol. 2020;27:2202-9.

23. Carrio I, Cowie MR, Yamazaki J, et al. Cardiac sympathetic imaging with mIBG in heart failure. JACC Cardiovasc Imaging. 2010;3:92-100.

24. Krum H, Schlaich M, Whitbourn R, et al. Catheter-based renal sympathetic denervation for resistant hypertension: a multicentre safety and proof-of-principle cohort study. Lancet. 2009;373:1275-81.

25. Hasking GJ, Esler MD, Jennings GL, et al. Norepinephrine spillover to plasma in patients with congestive heart failure: evidence of increased overall and cardiorenal sympathetic nervous activity. Circulation. 1986;73:615-21.

26. Florea VG, Cohn JN. The autonomic nervous system and heartfailure. Circ Res. 2014;114:1815-26.

27. KasamaS, ToyamaT, KumakuraH, etal. Effect of spironolactone on cardiac sympathetic nerve activity and left ventricular remodeling in patients with dilated cardiomyopathy. JAm Coll Cardiol. 2003;41:574-81.

28. Jacobson AF, Senior R, Cerqueira MD, et al. Myocardial iodine-123 meta-iodobenzylguanidine imaging and cardiac events in heart failure. Results of the prospective ADMIREHF (AdreView Myocardial Imaging for Risk Evaluation in Heart Failure) study. J Am Coll Cardiol. 2010;55:2212-21.

29. Feyz L, van Dalen BM, Geleijnse ML, et al. Effect of catheterbased renal denervation on left ventricular function, mass and (un)twist with two-dimensional speckle tracking echocardiography. JEchocardiogr. 2017;15:158-65. 